\title{
Conestato
}

\section{Diálogo entre as dimensões da competência em informação e os cursos de graduação em Arquivologia do sul do Brasil}

\author{
Fernanda Frasson Martendal \\ Mestranda; Universidade Federal de Santa Catarina, Florianópolis, SC, Brasil; \\ fernanda.martendal@ hotmail.com \\ Eva Cristina Leite da Silva \\ Doutora; Universidade Federal de Santa Catarina, Florianópolis, SC, Brasil; \\ eva.cristina@ufsc.br \\ Elizete Vieira Vitorino \\ Doutora; Universidade Federal de Santa Catarina, Florianópolis, SC, Brasil; \\ elizete.vitorino@ufsc.br
}

\begin{abstract}
Resumo: Este estudo busca identificar em que medida as quatro dimensões da competência em informação (técnica, estética, ética e política) relacionam-se ao perfil desejado para os egressos dos cursos de graduação em Arquivologia de três universidades do sul do Brasil: Universidade Estadual de Londrina, Universidade Federal de Santa Catarina e Universidade Federal do Rio Grande do Sul. No tocante aos aspectos metodológicos, identifica-se como pesquisa exploratória, documental e bibliográfica e propõe-se a pensar a Arquivologia como ciência que contempla aspectos teóricos, práticos, imbuídos de diretrizes e diálogos entre os profissionais, os acervos e seus usuários. A pesquisa considerou que as quatro dimensões da competência em informação estão relacionadas ao perfil dos egressos constantes nos Projetos Pedagógicos das três universidades pesquisadas e que tal ponderação contribui para pensar a Arquivologia em seu macro espaço.
\end{abstract}

Palavras-chave: Competência em informação. Arquivologia. Dimensões da competência em informação. Perfil dos egressos do curso de graduação em Arquivologia.

\section{Introdução}

Com o objetivo de relacionar, identificar e de interatuar com as necessidades de informação de uma sociedade da informação e do conhecimento, a Ciência da Informação se desenvolve, buscando tornar seu objeto de estudo inteligível e comunicável. Para isso, a informação precisa ser identificada, organizada, preservada e disseminada, respeitados possíveis graus de sigilo. 
Portanto, a Ciência da Informação é considerada como campo interdisciplinar, cuja multiplicidade de ramificações se nota expressada na Arquivologia, na Biblioteconomia e na Museologia, por exemplo, as quais também utilizam a informação como objeto de estudo. Para que existam, além disso, estas áreas necessitam conhecer seu entorno, os usuários que trabalharão e servir-se-ão destes recursos informacionais, o ambiente em que se inserem, as tecnologias utilizadas, com que parâmetros e para que fim.

Em razão da Arquivologia, a disseminação/difusão da informação nos arquivos é ponto central que se relaciona tanto à informação enquanto prova (jurídica, administrativa), quanto à salvaguarda de memórias de determinadas pessoas, instituições e/ou sociedade, e está permeada por saberes teóricometodológicos específicos, ou seja, determinadas habilidades. Para fomentar esta discussão, o presente estudo traz à tona o ensino de Arquivologia, como alicerce para que os profissionais, os acervos e os próprios usuários sejam parte da competência em informação, neste caso, aplicada diretamente à Arquivologia.

Para tanto, objetiva-se relacionar as quatro dimensões da competência em informação (técnica, estética, ética e política), apontadas pela literatura da área, ao prospectado para o perfil dos egressos dos cursos de graduação em Arquivologia e toma-se por base um Curso/Universidade de cada Estado da região Sul do Brasil, a saber: Universidade Estadual de Londrina, Universidade Federal de Santa Catarina e Universidade Federal do Rio Grande do Sul.

Os aspectos metodológicos aqui eleitos baseiam-se em pesquisa essencialmente bibliográfica, documental e exploratória, pois tratam de analisar os Projetos Pedagógicos dos cursos de graduação em Arquivologia das três universidades, especificamente no que se refere ao tópico denominado "Perfil dos egressos", proposto nos três cursos.

Ao eleger as universidades para compor este estudo, observou-se que, representativas da região Sul do Brasil, há cinco que possuem o curso de graduação em Arquivologia, segundo o Conselho Nacional de Arquivos (CONARQ) (2016): Universidade Federal de Santa Maria (UFSM), Universidade Federal do Rio Grande do Sul (UFRGS), Universidade Federal do 
Rio Grande (FURG), Universidade Estadual de Londrina (UEL) e Universidade Federal de Santa Catarina (UFSC). Todavia, não foi possível consultar os Projetos Pedagógicos dos cursos, nos sítios web de todas as cinco universidades, assim, não foram consideradas para o estudo a Universidade Federal de Santa Maria (UFSM) e a Universidade Federal do Rio Grande (FURG).

Ao considerar o processo de formação em Arquivologia, indicados nos Projetos Pedagógicos dos cursos analisados, leva-se em conta os aspectos teóricos e práticos que norteiam a profissão, além de suas diretrizes e construção de relações interpessoais e interinstitucionais. Portanto, este estudo busca contribuir, na perspectiva do ensino, para identificar a competência em informação neste contexto também informacional.

\section{A Ciência da Informação, a Arquivologia e seus trajetos históricos}

Como campo interdisciplinar, a Ciência da Informação leva em conta suas áreas correlatas, ou seja, as áreas do conhecimento que também utilizam a informação (não somente ela) como subsídio para seus objetivos específicos. De forma particular, a Arquivologia, a Biblioteconomia, a Museologia e a Ciência da Informação, são consideradas interdisciplinares ${ }^{1}$ e/ou transdisciplinares ${ }^{2}$, tendo em vista que trabalham intensivamente com a preservação e disseminação da informação, sob diferentes aspectos sociais, sejam culturais, políticos, econômicos, históricos ou memorialísticos, entre outros.

Em relação à interdisciplinaridade da Ciência da Informação, Borko (1968, p. 3, tradução nossa), em seu artigo intitulado Information Science: what is it?, assevera que:

[A] Ciência da informação [...] é uma ciência interdisciplinar derivada e relacionada a alguns campos como matemática, lógica, linguística, psicologia, tecnologia da computação, pesquisa operacional, artes gráficas, comunicação, biblioteconomia, administração e outros campos similares.

De acordo com as áreas correlatas à Ciência da Informação, observa-se pontos comuns nos quais é inserido o objeto informação, como por exemplo, no 
caso da tríade Arquivologia, Biblioteconomia e Museologia, ou seja, a informação e a disseminação nos arquivos, nas bibliotecas e nos museus.

Tais unidades merecem destaque, por serem campos de disseminação da informação e do conhecimento; espaços de atividades culturais, preservadores de memórias coletivas e também individuais. Assim, explana Araújo (2014, p. 160), quando afirma que a Arquivologia, a Museologia e a Biblioteconomia:

[...] possuem muito mais em comum do que uma dimensão
informacional. Elas também partilham de uma dimensão
comunicativa (todas buscam interlocução com públicos),
administrativa (instituições e recursos que precisam ser geridos),
educacional (todas atuam no âmbito formativo e pedagógico).

Nesta perspectiva de complementaridade entre as áreas, nota-se que o objetivo comum de gerir a informação de maneira conexa aos métodos e técnicas inerentes a cada área é primaz, pois assim a informação pode ser disponibilizada ao público de maneira íntegra. Dando enfoque às teorias e métodos de cada uma destas ciências, os profissionais relacionados a elas também exercerão suas funções para o fim de preservar e/ou disponibilizar informações ao público, seguindo os princípios éticos da profissão, em prol do acesso à informação enquanto bem educativo e cultural.

Contemporaneamente, é a informação orgânica o objeto de estudo da Arquivologia e, de acordo com a sua produção, seu desenvolvimento e disseminação, vão incorporando-se técnicas para geri-la, melhor usá-la e preservá-la, a fim de que se mantenha acessível.

Manter o arquivo acessível é um dos principais compromissos do arquivista para com seu público. Se um arquivo é público, deve estar aberto à sociedade, e se privado, ao público que lhe cabe. Em ambos os casos, demanda uma competência própria, que é construída ao longo do processo educacional do arquivista, o qual perpassa os cursos de graduação, compreendidos pela educação superior, quando se aborda a realidade brasileira.

É sob este olhar que se insere a temática da competência em informação: competência esta inerente ao profissional que faz uso intensivo da informação como objeto de trabalho e de estudo e que se desenvolve e é mobilizada por 
meio de um conjunto de comportamentos, conhecimentos, habilidades, valores, atitudes, etc.

\section{A competência em informação}

Caracterizada por um conjunto de comportamentos, conhecimentos, habilidades, valores e atitudes voltadas ao cenário informacional, trata-se da competência que o profissional da informação desenvolve para lidar com seu objeto de trabalho e de estudo, de maneira a conhecê-lo, caracterizá-lo, geri-lo e disponibilizá-lo quando necessário.

Para Dudziak (2003, p. 28), a competência em informação é definida como:

[...] o processo contínuo de internalização de fundamentos conceituais, atitudinais e de habilidades necessário à compreensão e interação permanente com o universo informacional e sua dinâmica, de modo a proporcionar um aprendizado ao longo da vida.

Considerando seu conjunto de habilidades composto por cinco diretrizes norteadoras, definidas pela American Library Association (ALA) ${ }^{3}$ (2016b) - (1) determinar a natureza e a extensão da informação; (2) acessar a informação efetiva e eficientemente; (3) avaliar a informação e suas fontes criticamente e incorporá-la a um sistema; (4) usar a informação efetivamente para um propósito específico; e (5) entender os aspectos econômicos, legais e sociais relacionados ao uso da informação e acessá-la e usá-la ética e legalmente - a competência em informação apresenta-se aplicável às ciências que utilizam a informação como seu objeto de estudo. Inicialmente, em diálogos mais profícuos com a Biblioteconomia, observa-se a aplicabilidade de suas diretrizes e preceitos também a outras ciências, como é o caso da Arquivologia.

Referidas diretrizes, porém, necessitam ser permeadas por outras questões que não somente a técnica inerente às profissões, pois, visto que serão operacionalizadas por profissionais, estarão carregadas de impressões pessoais e de caracteres sociais, ou seja, apresentam-se aí as diversas dimensões desta competência no trabalho do profissional da informação.

Neste sentido, a competência em informação pode ser estudada sob o alicerce de algumas dimensões (VITORINO, 2016), porém, para efeitos deste 
estudo, adotou-se as quatro dimensões da competência em informação trazidas por Rios (2006), que se relacionam diretamente (Quadro 1):

Quadro 1 - Definições das dimensões da competência em informação

\begin{tabular}{|l|l|}
\hline $\begin{array}{l}\text { Dimensão } \\
\text { estética }\end{array}$ & $\begin{array}{l}\text { "A Dimensão Estética está ancorada nos conceitos de Estética, } \\
\text { resgatados da Filosofia. Diz respeito à sensibilidade, a criatividade, a } \\
\text { solidariedade e, direcionado ao fazer do Bibliotecário, implica em } \\
\text { resgatar os aspectos humanos, culturais e sociais, pouco explorados em } \\
\text { virtude de uma formação predominantemente técnica, desde a década de } \\
1930 . " \text { (ORELO; VITORINO, 2013, p. 1). }\end{array}$ \\
\hline $\begin{array}{l}\text { Dimensão } \\
\text { política }\end{array}$ & $\begin{array}{l}\text { Encontra-se aliada "[...] ao desenvolvimento das sociedades } \\
\text { democráticas [e propõe a observação de que] uma cidadania ativa e } \\
\text { responsável requer que as pessoas estejam aptas e motivadas para } \\
\text { exercer seus direitos e deveres em relação à comunidade e ao Estado, } \\
\text { participando assim da vida pública. A cidadania, como atividade que } \\
\text { visa a um bem comum, articula-se diretamente com o conceito de } \\
\text { política." (VITORINO; PIANTOLA, 2011, p. 106-107). }\end{array}$ \\
\hline Dimensão ética & $\begin{array}{l}\text { "Esta, no âmbito da Competência Informacional, refere-se ao uso legal e } \\
\text { responsável da informação, fundamentado nas leis e normas que regem } \\
\text { o uso da informação em cada país, e nos princípios éticos de respeito, } \\
\text { justiça, solidariedade e compromisso, que resultam no bem coletivo e na } \\
\text { cidadania." (PELLEGRINI; VITORINO, 2015, p. 4). }\end{array}$ \\
\hline Dimensão & $\begin{array}{l}\text { "A ênfase sobre a técnica explica-se pelo fato de ela constituir a } \\
\text { dimensão mais evidente da competência informacional, na medida em } \\
\text { que é o meio de ação do indivíduo no contexto da informação." } \\
\text { (VITORINO; PIANTOLA, 2011, p. 102). }\end{array}$ \\
\hline
\end{tabular}

Fonte: Elaborado pelas autoras (2016), baseado em Orelo e Vitorino (2013), Pellegrini e Vitorino (2015) e Vitorino e Piantola (2011).

As dimensões mostradas no Quadro 1 fazem parte do ofício diário do profissional da informação e, no caso da Arquivologia, esta relação técnica, ética, estética e política está atrelada ao que se conhece por gestão documental que, conforme Jardim (1987, p. 35),

[...] cobre todo o ciclo de existência dos documentos desde sua produção até serem eliminados ou recolhidos para arquivamento permanente, ou seja, trata-se de todas as atividades inerentes às idades corrente, $[. .$.$] intermediária [e permanente].$

Considerando que a competência em informação favorece as boas práticas em relação à gestão da informação, também é possível identificá-la como elemento relevante à formação dos profissionais da informação que, como gestores, são orientados a agir ética, estética, política e tecnicamente, em relação aos acervos e aos usuários da informação. 


\section{Da Arquivologia e da competência do arquivista}

Devido ao acervo e ao histórico institucional, os arquivos se apresentam como entidades que fazem menção a aspectos culturais e educativos relacionados a seu público, o que ocorre de maneira mais enfática quando tais arquivos são de caráter público. A Organização das Nações Unidas, no Art. XXII da Declaração Universal dos Direitos Humanos (1948, p. 12, grifo nosso), menciona que:

Todo ser humano, como membro da sociedade, tem direito à segurança social, à realização pelo esforço nacional, pela cooperação internacional e de acordo com a organização e recursos de cada Estado, dos direitos econômicos, sociais e culturais indispensáveis à sua dignidade e ao livre desenvolvimento da sua personalidade.

Nesta mesma linha de raciocínio, no Brasil, a Lei $\mathrm{n}^{\circ} 12.343$, de 2 de dezembro de 2010, que institui o Plano Nacional de Cultura, afirma como um de seus princípios a promoção do "[...] direito à memória por meio dos museus, arquivos e coleções.” (BRASIL, 2010). Em contexto macro, reconhece-se o arquivo como unidade cultural e de informação.

O arquivo possui fonte orgânica de informação, produzida no decorrer da história de cada região, referente a fatos da vida da própria sociedade, em contexto macro ou micro e que pode, por meio da mediação do arquivista, colaborar em leituras, pesquisas e estudos sobre a história da humanidade e das coisas. Ao cooperar para o desenvolvimento do saber social e da cultura, o arquivo aparece também como entidade educativa.

O ensino dos arquivos é cada vez mais aclamado como uma tarefa fundamental na sociedade contemporânea, pois em um mundo de informação globalizada e sem referenciais, o universo arquivístico dos contextos serve como sólida orientação e referencial (ALDABALDE, 2012, p. 199).

Dada a observância à Declaração Universal dos Direitos Humanos, nota-se que o acesso aberto aos arquivos públicos deve ser promovido a todo cidadão e que, para tanto, é necessário suscitar a necessidade de o cidadão buscar o arquivo também como fonte de saber, assim como o fazem nas 
bibliotecas, ou museus, por exemplo. Esta necessidade pode surgir a partir de uma situação problema, ou também por deleite, por relações afetivas, pelo suscitar de possíveis memórias.

Neste sentido, ocorrem os impasses inerentes à disponibilização e à preservação da memória documental no mundo. $\mathrm{O}$ arquivo, para ser pesquisado, precisa estar organizado de maneira consoante à gestão documental arquivística, que engloba as funções de classificação, preservação, avaliação, descrição, disseminação, etc. A gestão documental arquivística é condição elementar para que o arquivo possa ser visualizado como lugar de cultura e não como depósito de papéis (BELLOTTO, 2006).

Ainda assim, o caráter formativo e/ou educativo do arquivo é visível. Todavia, ele está correlacionado à formação de seus colaboradores, especialmente bacharéis em Arquivologia, pois sua competência compreende, para além da gestão documental, uma formação política, ética, comprometida com o estatuto do documento, com a comunidade e com a instituição como ponto de encontro do cidadão.

Assim, os arquivistas necessitam prestar atenção em seus usuários, fazer com que se sintam acolhidos para pesquisar e estudar sobre o que thes interessar. Questiona-se, por que não, então, assumirem um papel de defensores da preservação daquela instituição e de suas fontes documentais, para que permaneçam aptas às consultas realizadas pelos usuários e vivas as memórias e histórias ali contidas ou suscitadas no inter-relacionamento entre fontes, usuários e arquivistas?

Outro aspecto a ser suscitado a respeito do arquivo enquanto instituição educativa são os programas de educação por meio da disseminação do arquivo nas comunidades, levando-o à rota turística da cidade, por exemplo, como afirma Bellotto (2006). Estas estratégias provocam nos integrantes do arquivo o pensar na população que não conhece a instituição e o acervo e mesmo nunca realizou atividades de pesquisa. Para este público, o arquivo também deve estar aberto e é função do arquivista buscar métodos que promovam o acesso do cidadão à informação nele contida. 
Assim, há necessidade de programas para tornar o arquivo acessível para pessoas com necessidades especiais de locomoção, visão, audição, fala, ou cognição. Torná-lo ambiente de ensino e de aprendizagem a quem teve experiências educativas em ambientes formais e não formais e àqueles que ainda não tiveram oportunidades de vivências nos arquivos (ALDABALDE, 2012).

Para que estas ações aconteçam, portanto, as instituições arquivísticas e de ensino devem incorporar atividades que estimulem os arquivistas a pensarem de que maneira o acervo estará disponibilizado a seus usuários. Na medida em que se compreende que um acervo é informação arquivística a ser gerida, é possível pensar em estratégias didáticas que, ao serem incorporadas ao processo formativo do estudante de Arquivologia, dão base para uma discussão mais ampla no que tange às maneiras de lidar com a documentação e com seus usuários, utilizando-se da técnica, da ética, da estética (sensibilidade, criatividade etc.) e de políticas institucionalizadas.

Neste caso, também é pertinente identificar a competência arquivística, definida a partir da acepção da competência em informação, porém aplicada aos arquivos e à Arquivologia. Blundell (2013, p. 1, tradução nossa) estabelece esta relação quando defende que:

Competência em informação torna-se competência arquivística quando um foco especial é delineado em duas áreas: 1) a importância dos documentos de fonte primária para a narrativa da competência em informação, e 2) a ampliação da utilidade potencial do arquivo ou coleção especial além do físico (por exemplo, o reino digital) para outras necessidades do usuário.

Quando abordados sobre ações para o desenvolvimento da competência arquivística nas universidades e nas instituições arquivísticas, estes conceitos estão alicerçados na relação entre a Pedagogia e o arquivo; nas maneiras de ensinar e de aprender, além de compreender a relação ensino-aprendizagem como um conjunto de vias, que fomenta a troca e resignificações, incluindo o contexto sócio-histórico a que o sujeito está atrelado, assim, abordando o caráter social da Arquivologia (ALDABALDE, 2012).

A competência inerente à profissão do arquivista encontra-se alicerçada no estudo teórico-metodológico que acompanhou o estudante por todo o período 
em que esteve inserido na educação superior. As informações estudadas a respeito do ciclo de vida dos documentos, por exemplo, e em relação a como preservar um acervo, ou classificá-lo, são regidas por conjuntos de habilidades incorporados aos conteúdos estudados, a fim de que o profissional possa entender como funciona um arquivo.

Carini (2016) afirma que o arquivista para ser competente em informação neste âmbito deve trabalhar sob o respaldo de seis diretrizes que o capacitarão para atuar em arquivos, seja de que natureza forem: conhecer o acervo, interpretá-lo, avaliá-lo, usá-lo, acessá-lo e seguir princípios éticos. Estas diretrizes estão diretamente relacionadas às quatro dimensões da competência em informação, que podem ser aplicadas à Arquivologia como um todo, desde as etapas da formação do arquivista até a prática diária da profissão.

\section{As dimensões da competência em informação nos cursos de graduação em}

\section{Arquivologia}

o aumento da demanda de pesquisa aos documentos, identificado após o período do Romantismo, provoca na Europa o desejo de criar cursos de formação profissional de arquivistas (BOTTINO, 1994), pois era notada a necessidade de incorporar às instituições pessoas que entendessem de registros e documentos guardados nos arquivos e soubessem cuidá-los. A partir daí, as primeiras reflexões acerca do ensino da Arquivologia abarcavam a formação de profissionais e a incorporação de técnicas específicas aplicadas principalmente à conservação e guarda de referida documentação (MARQUES, 2011).

Na América Latina, a exemplo, o ensino da Arquivologia foi construído a partir de observações do espaço europeu e o desenvolvimento de sua organização documental relacionado às práticas europeias e norte-americanas (TANODI, 1985). Neste sentido, o primeiro curso para formação de arquivistas em ambiente latino-americano encontra-se na Argentina, datado no ano de 1959 e iniciado pela Universidad Nacional de Córdoba (UNC), localizada em província homônima, dentro da denominada Escuela de Bibliotecarios y Archiveros (MARQUES, 2011). No Brasil, o primeiro curso para formação de arquivistas data o ano de 1960 e localizava-se no espaço do Arquivo Nacional 
brasileiro. Após algumas modificações em sua estrutura, passou a pertencer à Escola de Arquivologia da Universidade Federal do Estado do Rio de Janeiro (UNIRIO) (MARQUES, 2011).

A partir da criação destes cursos, conteúdos curriculares foram propostos, cada vez mais aliados aos princípios basilares da Arquivologia, ao perfil desejado para o profissional arquivista, ao local onde se prospectava seu ofício e ao público que se serviria das informações orgânicas. Aspectos estes que requeriam e requerem a junção de habilidades, entre os profissionais e o público, para a compreensão das informações arquivísticas e a interação com elas.

Quando a competência em informação é abordada e sua concepção e desenvolvimento são estudados, há a correlação com a Biblioteconomia e Documentação, área a partir da qual obteve destaque, quando sua definição foi concebida pela ALA. De acordo com esta definição, a competência em informação relaciona-se a dois caminhos a serem seguidos: o dos usuários internos, sejam eles os funcionários das bibliotecas, bem como o dos usuários externos, quais sejam os públicos aos quais o conteúdo bibliográfico serve.

Porém, ao longo de seu desenvolvimento como disciplina, a competência em informação aparece relacionada também a outros campos correlatos à Ciência da Informação e que, por isso, utilizam-na como objeto de estudo, como é o caso da Arquivologia. Nota-se, desta maneira, relevante câmbio de rota, pois já não é somente a biblioteca seu alvo de aplicação.

A formação superior em Arquivologia, que outorga o título de Bacharel em Arquivologia, identifica-se na modalidade de curso de graduação, que capacita o estudante para atender às demandas de mercado na área de arquivos, as quais são pautadas pelas habilidades apreendidas pelos arquivistas, a fim de que ocupem os espaços em que possam atuar. A Classificação Brasileira de Ocupações (CBO) define algumas destas habilidades, de maneira geral:

[Os arquivistas] organizam documentos e informações. Orientam usuários e os auxiliam na recuperação de dados e informações. Disponibilizam fonte de dados para usuários. Providenciam aquisição de material e incorporam material ao acervo. Arquivam documentos, classificando-os segundo critérios apropriados para armazená-los e conservá-los. Prestam serviço de comutação, 
alimentam base de dados e elaboram estatísticas. Executam tarefas relacionadas com a elaboração e manutenção de arquivos, podendo ainda, operar equipamentos reprográficos, recuperar e preservar as informações por meio digital, magnético ou papel. (BRASIL, 2016).

Couture, Martineau e Ducharme (1999), no sentido de propor áreas temáticas para a pesquisa em Arquivologia, apresentam nove, identificadas por: Objeto e finalidade da arquivística, Arquivos e sociedade, História dos arquivos e da arquivística, Funções arquivísticas, Gestão dos programas e dos serviços de arquivos, Tecnologias, Suportes e tipos de arquivos, Meio profissional dos arquivos e Problemas particulares relativos aos arquivos.

Ao mesmo tempo em que são apresentadas como campos de pesquisa inerentes à área da Arquivologia, estas nove áreas também são inseridas nos Projetos Pedagógicos relacionados aos cursos de graduação das universidades e definidos por Anastasiou como projetos que derivam de instituições sociais (as universidades), referem-se aos cidadãos e têm

[...] como valor central a cidadania, o que se refletirá nas escolhas e na tomada de decisões quanto à organização curricular, das quais decorrerão objetivos, conteúdos, definições metodológicas e formas de acompanhamento. ( ANASTASIOU, 2007, p. 44-45).

Quanto ao programa de disciplinas a cursar pelos estudantes, este documento sofre modificações, com base nas características de cada curso de graduação, de cada universidade, do entorno em que está inserido (ANASTASIOU, 2007), porém as adequações se restringem a esses aspectos, visto que a Arquivologia se baseia em alguns alicerces que, ao serem contemplados comumente por todos os cursos de graduação em Arquivologia, colaboram para alcançar o objetivo profissional elucidado pela CBO.

As nove áreas supracitadas apresentam relação com o processo de formação profissional em Arquivologia, pois contemplam habilidades, conteúdos e temáticas (a competência em si) que o estudante deve desenvolver no curso e utilizar ao ingressar no mercado de trabalho. Monteiro (2010, p. 7) define o termo profissão em seu sentido restrito, destacando que consiste 
mais ou menos longa, geralmente em instituições de ensino superior. (MONTEIRO, 2010, p. 7).

As habilidades consistem, no âmbito da Arquivologia, no que-fazer profissional, permeado pelas teorias e técnicas para a prática da profissão, em consonância com os direitos e deveres do arquivista e sua relação com a comunidade arquivística. Este conjunto de requisitos é retratado no perfil traçado nas Instituições de Ensino Superior (IES) em relação ao que esperam dos estudantes egressos.

A relação estabelecida entre os objetivos que cada curso de graduação elabora, como o que almeja para o estudante egresso, também está permeada pelos contextos em que estão inseridos e, por seus caracteres sócio, político, econômico, cultural, ético, disciplinares, etc., e identificam-se com as quatro dimensões da competência em informação, defendidas fortemente por Vitorino e Piantola quando afirmam que “[...] ser competente informacional também implicaria possuir habilidades individuais considerando ao mesmo tempo o âmbito da coletividade e das relações sociais.” (PIANTOLA, 2011, p. 101).

Nesta perspectiva e a partir da análise dos perfis dos egressos de três cursos de graduação em Arquivologia de universidades da região sul do Brasil, é possível pautar conexões entre as quatro dimensões da competência em informação e os objetivos destes perfis de egressos, a fim de confirmar a presença da competência arquivística no macro espaço da competência em informação.

Os quadros 2, 3, 4 e 5 exemplificam cada uma das quatro dimensões da competência em informação, buscando relacioná-las aos objetivos incorporados aos perfis dos egressos dos cursos de graduação em Arquivologia das IES Universidade Federal do Rio Grande do Sul (UFRGS), Universidade Federal de Santa Catarina (UFSC) e Universidade Estadual de Londrina (UEL).

Cabe destacar que, embora tenham sido consideradas para este estudo duas universidades federais e uma estadual, isto não interfere na coleta dos dados, pois as diretrizes curriculares dos cursos de graduação em Arquivologia no Brasil, em sua totalidade, são regidas pelo Parecer CNE/CES 492/2001 (BRASIL, 2001). Outro fator a ponderar quando da análise dos Projetos Pedagógicos dos cursos, consiste em apresentar alguns dados que podem 
interferir nos resultados da pesquisa aqui empreendida: dentre as IES pesquisadas, a UEL tem maior antiguidade quanto a seu curso de graduação em Arquivologia, cuja data de criação é 1998. Os cursos na UFRGS e na UFSC são mais recentes, datando respectivamente os anos 1999 e 2009. Semelhanças também precisam ser consideradas: as três universidades aderem ao mesmo período de duração dos cursos de graduação em Arquivologia, que totaliza quatro anos, divididos em oito semestres letivos.

Mais à frente, o Quadro 2 apresenta a dimensão ética nas três universidades pesquisadas sob o foco do perfil do egresso. A dimensão ética, segundo afirmam Vitorino e Piantola (2011, p. 105-106), está baseada no caráter crítico inerente a ela e este caráter:

[...] está no cerne da ideia de competência informacional, já que o indivíduo que é efetivamente competente em informação é capaz de tomar posição, assumir uma postura crítica diante de determinadas informações, o que requer, na maioria das vezes, um julgamento de valor.

Praticar o comportamento ético em relação à informação significa ainda utilizá-la de modo responsável, sob a perspectiva da realização do bem comum.

Portanto, aspectos como a apropriação de valores de cidadania, justiça e ética profissional, a utilização de recursos racionalmente, a crítica e a avaliação da informação e a reflexão sobre o comportamento ético em relação à atuação profissional, provocam na Arquivologia relação com o código de ética da profissão, que regulamenta essas questões.

Quadro 2 - A dimensão ética da competência em informação e o perfil do egresso

\begin{tabular}{|c|c|}
\hline Objetivos & Universidade \\
\hline $\begin{array}{l}\text { Apropriação e internalização de valores de cidadania, responsabilidade social, justiça e } \\
\text { ética profissional; }\end{array}$ & UFRGS \\
\hline Identificar as fronteiras que demarcam o seu campo de conhecimento; & \multirow{3}{*}{ UFSC } \\
\hline Elaborar, coordenar, executar e avaliar planos, programas e projetos; & \\
\hline $\begin{array}{l}\text { Responder a demandas de informação produzidas pelas transformações que caracterizam } \\
\text { o mundo contemporâneo; }\end{array}$ & \\
\hline
\end{tabular}




\begin{tabular}{|l|l|}
\hline privadas. & \\
\hline Utilizar racionalmente os recursos disponíveis; & \\
\hline $\begin{array}{l}\text { Criticar, investigar, propor, planejar, executar e avaliar recursos e produtos de } \\
\text { informação; }\end{array}$ & UEL \\
\hline $\begin{array}{l}\text { Assimilar os novos conhecimentos científicos e/ou tecnológicos e refletir acerca do } \\
\text { comportamento ético que a sociedade espera de sua atuação e de suas relações com o } \\
\text { contexto cultural, socioeconômico e político; }\end{array}$ & \\
\hline
\end{tabular}

Fonte: Elaborado pelas autoras (2016), com base em Universidade Federal do Rio Grande do Sul

(2014), Universidade Estadual de Londrina (2013) e Universidade Federal de Santa Catarina (2015).

A ética, na vida profissional do arquivista, constitui-se como regras de conduta necessárias à prática tanto com os usuários, como diretamente em relação aos documentos custodiados sob seus cuidados. Respeitar os graus de sigilo de um acervo, por exemplo, significa utilizar princípios éticos para tal fim, como assevera o Conselho Internacional de Arquivos (CIA) em sua publicação Código de Ética do Arquivista, em um de seus tópicos: "O primeiro dever dos arquivistas é de manter a integridade dos documentos que são valorizados por seus cuidados e sua vigilância." (CONSELHO INTERNACIONAL DE ARQUIVOS, 1996, p. 1).

Esta dimensão relaciona-se diretamente à dimensão política da competência em informação, pois ambas tratam do contato com a sociedade que, neste caso, utiliza a informação arquivística. Neste sentido, ser político é considerar os diferentes públicos a que um arquivo pode servir, ter em conta os distintos modos de disponibilizar a informação, para que diferentes pessoas possam acessá-la. No Quadro 3, apresenta-se os objetivos quanto ao perfil do egresso do Curso de graduação em Arquivologia e a conexão destes com a dimensão política da competência em informação.

Quadro 3 - A dimensão política da competência em informação e o perfil do egresso

\begin{tabular}{|l|c|}
\hline \multicolumn{1}{|c|}{ Objetivos } & Universidade \\
\hline $\begin{array}{l}\text { Capacidade de atuar em equipes inter e multidisciplinares e multifuncionais, com } \\
\text { curiosidade e atitude investigativa no contexto de atuação profissional que promova } \\
\text { a criatividade e inovação na resolução de problemas, recorrendo às teorias } \\
\text { arquivísticas e suas relações interdisciplinares; }\end{array}$ & UFRGS \\
\hline
\end{tabular}


Formação humanística e visão global que o habilite a compreender o meio social, político, econômico e cultural no qual está inserido e a tomar decisões em um mundo diversificado e interdependente;

Flexibilidade e pró-atividade diante das mudanças das realidades profissionais;

Formular e executar políticas institucionais;

Traduzir as necessidades de indivíduos, grupos e comunidades nas respectivas áreas de atuação;

Compreender o estatuto probatório dos documentos de arquivo;

Identificar o contexto de produção de documentos no âmbito de instituições públicas e privadas;

Formular e executar políticas institucionais;

Elaborar, coordenar, executar e avaliar planos, programas e projetos;

Traduzir as necessidades de indivíduos, grupos e comunidades nas respectivas áreas de atuação;

Responder a demandas sociais de informação produzidas pelas transformações tecnológicas que caracterizam o mundo contemporâneo;

Ter consciência da importância social da profissão como possibilidade de desenvolvimento social e coletivo;

Compreender o estatuto probatório dos documentos de arquivo;

Identificar o contexto de produção de documentos no âmbito de instituições públicas e privadas;

Planejar, organizar, executar, gerenciar e avaliar serviços, unidades e sistemas de informação arquivísticos.

Fonte: Elaborado pelas autoras (2016), com base em Universidade Federal do Rio Grande do Sul

(2014), Universidade Estadual de Londrina (2013) e Universidade Federal de Santa Catarina

(2015).

Ao que parece, é na dimensão política que estão concentrados o maior número de objetivos relativos ao que as universidades almejam alcançar com seus cursos de graduação em Arquivologia. Pontos como gerenciar serviços de informação arquivísticos, identificar contextos de produção documentais, executar políticas institucionais, responder a demandas de informações, bem como ter capacidade para atuar em equipes multidisciplinares, são desafios interpostos pela dimensão política da competência em informação. 
Para Vitorino e Piantola (2011, p. 107), a dimensão política é definida a partir da concepção de que a sociedade é política, em sua cotidianidade: “Quando se fala em 'homem político', tem-se em mente o sentido da dimensão da competência em administrar o próprio trajeto histórico, mudando a natureza e as relações sociais".

O egresso em Arquivologia busca desenvolver habilidades para lidar com o público usuário do arquivo, bem como para identificar necessidades de busca de informação, a partir de seu conhecimento sobre a instituição em que atua, sobre seus contextos, seu entorno. Para isso, envolve-se também na concepção e execução de projetos que busquem maneiras de adequar a instituição e seus serviços para receber comodamente seu público, ou fazer um caminho inverso: estabelecer diretrizes para que os documentos possam ser transportados em segurança para a pesquisa de seus usuários.

Esta dimensão, porém, somente atrelada à ética não cumpre o que um curso de graduação em Arquivologia deseja transmitir como conhecimento a seus discentes. É necessária a operação destes elementos juntamente à técnica inerente à profissão, para que as tarefas cotidianas de higienização, classificação e guarda documentais sejam coerentes ao tipo de arquivo em que estão sendo empregadas. Desta forma, é na dimensão técnica que estão inseridas as atividades relacionadas ao "saber-fazer" e à ação propriamente dita. O Quadro 4 mostra os objetivos relacionados ao perfil do egresso em Arquivologia e a conexão destes com a dimensão técnica.

Quadro 4 - A dimensão técnica da competência em informação e o perfil do egresso

\begin{tabular}{|l|l|}
\hline \multicolumn{1}{|c|}{ Objetivos } & Universidade \\
\hline $\begin{array}{l}\text { Formação técnica e científica para atuar na Arquivologia, além de desenvolver } \\
\text { atividades específicas da prática profissional em consonância com as demandas globais, } \\
\text { nacionais e regionais e orientada para os processos de produção, usos e fluxos da } \\
\text { informação, bem como sua recuperação e preservação; }\end{array}$ & UFRGS \\
\hline $\begin{array}{ll}\text { Gerar serviços a partir dos conhecimentos adquiridos e divulgá-los; } \\
\text { Planejar e elaborar instrumentos de gestão de documentos de arquivo que permitam sua } \\
\text { organização, avaliação e utilização; }\end{array}$ & UFSC \\
\hline \multirow{2}{*}{ Realizar operações de classificação, descrição e difusão. } & \\
\hline
\end{tabular}


Gerenciar o preparo, recebimento, distribuição, higienização e controle da documentação;

Treinar e supervisionar o trabalho na organização: escolas, hospitais, escritórios, empresas especializadas (portuárias) e indústrias;

Gerar produtos a partir dos conhecimentos adquiridos e divulgá-los;

Planejar e elaborar instrumentos de gestão de documentos de arquivo que permitam sua organização, avaliação e utilização;

Realizar operações de arranjo, descrição e difusão de acervos arquivísticos;

Trabalhar com fontes de informação de qualquer natureza;

Planejar e elaborar instrumentos de gestão de documentos de arquivo que permitam sua organização, avaliação e utilização;

Realizar operações de arranjo, descrição e difusão de acervos arquivísticos;

Trabalhar com fontes de informação de qualquer natureza;

Processar a informação registrada em diferentes tipos de suportes, mediante a aplicação de conhecimentos teóricos e práticos de coleta, processamento, armazenamento e difusão da informação.

Fonte: Elaborado pelas autoras (2016), com base em Universidade Federal do Rio Grande do Sul (2014), Universidade Estadual de Londrina (2013) e Universidade Federal de Santa Catarina (2015).

Inerente à dimensão técnica, é encontrado o corpo fixo dos cursos de graduação em Arquivologia. Como área que incorpora métodos e técnicas para que o acesso e a preservação documental sejam realizados conforme princípios da ciência e éticos da profissão, ela reúne técnicas para que estes objetivos sejam alcançados. O emprego de técnicas no tratamento dos arquivos e a observação da necessidade de sua continuidade, para que eles cumprissem suas funções, foram precursores para a posterior teorização da área e criação dos cursos de graduação em Arquivologia (MARQUES, 2011).

Na competência em informação, a dimensão técnica representa " [...] uma habilidade ou forma requerida para a realização de determinada ação ou para a execução de um ofício.” (VITORINO; PIANTOLA, 2011, p. 102). Neste sentido, a Arquivologia reúne aspectos relacionados à dimensão técnica: há princípios, funções e normatizações arquivísticas exemplificadores dessas questões. 
Divididas em sete (criação, classificação, avaliação, descrição, conservação, aquisição e difusão), as funções arquivísticas compreendem o emprego de técnicas nos acervos desde o início de seu ciclo documental, ou seja, desde a criação documental à guarda permanente, ou eliminação. Os métodos empregados nestas sete funções colaboram para que a preservação do arquivo e seu acesso sejam assegurados e os direitos de seus usuários, resguardados (COUTURE, 2003).

O arquivista competente - segundo a dimensão técnica - está apto a realizar as funções da gestão documental arquivística, a planejar e gerenciar os arquivos, a relacionar-se com as demandas de informação e seus fluxos, bem como trabalhar com fontes de informação de qualquer natureza. O desenvolvimento teórico-prático-metodológico do arquivista, permeado pela aplicação da técnica, também se reveste de estratégias, estas permeadas pela sensibilidade, criatividade, resolução de problemas e transformação da técnica propriamente dita. Este é o trabalho da dimensão estética da competência em informação. Os objetivos presentes no perfil do egresso em Arquivologia estão conectados com a dimensão estética da competência em informação, conforme pode ser visto no Quadro 5.

Quadro 5 - A dimensão estética da competência em informação e o perfil do egresso

\begin{tabular}{|l|l|}
\hline \multicolumn{1}{|c|}{ Objetivos } & Universidade \\
\hline $\begin{array}{l}\text { Compreensão da necessidade do contínuo aperfeiçoamento profissional e predisposição } \\
\text { para o aprendizado contínuo. }\end{array}$ & UFRGS \\
\hline $\begin{array}{l}\text { Desenvolver e utilizar novas tecnologias; } \\
\text { Desenvolver atividades profissionais autônomas, de modo a orientar, dirigir, assessorar, } \\
\text { prestar consultoria, realizar perícias e emitir laudos técnicos e pareceres; }\end{array}$ & \\
\hline $\begin{array}{l}\text { Planejar e coordenar a área de arquivo ao implementar rotinas de trabalho, esquematizar } \\
\text { as funções, estabelecer a política de arquivo visando sempre que o atendimento ao cliente } \\
\text { seja de elevado padrão técnico e humano; }\end{array}$ & UFSC \\
\hline $\begin{array}{l}\text { Oferecer suporte de marketing e consultoria com orientação ao atendimento ao } \\
\text { consumidor, pesquisas de produtos arquivísticos, fortalecer a garantia de qualidade na } \\
\text { produção seja de empresas, indústrias e demais instituições públicas e privadas; }\end{array}$ & \\
\hline $\begin{array}{l}\text { Coordenar as pesquisas de produtos, testes de equipamentos arquivísticos e de } \\
\text { atendimento ao consumidor; }\end{array}$ & \\
\hline
\end{tabular}


Realizar pesquisas: em documentos, em laboratórios de pesquisa documental e arquivos históricos/tecnológicos, de instituições de ensino superior e centros científicos para investigar os suportes e as propriedades dos documentos.

Desenvolver e utilizar novas tecnologias;

Desenvolver atividades profissionais autônomas, de modo a orientar, dirigir, assessorar, prestar consultoria, realizar perícias e emitir laudos técnicos e pareceres;

Interagir e agregar valores aos processos de geração, transferência e uso da informação em todo e qualquer ambiente;

Realizar pesquisas relativas a produtos, processamento, transferência e uso da informação. Fonte: Elaborado pelas autoras (2016), com base em Universidade Federal do Rio Grande do Sul (2014), Universidade Estadual de Londrina (2013) e Universidade Federal de Santa Catarina (2015).

Relacionada às habilidades inerentes ao profissional arquivista, sobre como difundir a informação arquivística aos usuários, ou mesmo como implementar a identidade visual do arquivo, ou que instrumentos de pesquisa criar para que o acervo possa ser acessado, a dimensão estética da competência em informação auxilia o profissional no âmbito estratégico e visual da informação.

Segundo as autoras Vitorino e Piantola (2011, p. 103-104), a dimensão estética:

[...] transmite-se aos indivíduos tanto a partir de referenciais do mundo exterior, com base em dados empíricos, verificáveis, objetivos, quanto do interior, por meio da intuição, da sensibilidade, da imaginação e da reflexão pessoal. Nesse sentido, ao dizermos que existe uma dimensão estética na competência informacional, referimo-nos à experiência interior, individual e única do sujeito ao lidar com os conteúdos de informação e a sua maneira de expressála e agir sobre ela no âmbito coletivo.

Esta dimensão incorpora à gestão documental arquivística característica da "beleza" inserida no trato diário com o acervo, desde a criação dos itens documentais até seu desenvolvimento, a criação de instrumentos de pesquisa relacionados a eles, bem como sua divulgação ao público. O caráter estético de um arquivo se apresenta também quando ações para preservação física (independentemente do suporte) são incorporadas ao plano de gestão arquivística da instituição, ou quando ações para a gestão interna, como a 
organização do acervo, a elaboração de planos de classificação, ou tabelas de temporalidade e destinação de documentos, são desenvolvidos, para que o arquivo e sua informação se tornem acessíveis também aos usuários internos da instituição.

\section{Considerações finais}

A competência em informação, como disciplina inserida na Ciência da Informação, relaciona-se com o saber lidar com as fontes de informação e seu público, num processo em que a afinidade com o acervo dote o usuário de autonomia para buscar as informações de que necessita, fazendo-o ter proximidade ao arquivo, à biblioteca, ou outra unidade de informação. Para tanto, as dimensões da competência em informação (ética, estética, política e técnica) corroboram para minimizar ou sanar possíveis lacunas na ligação entre o profissional, o usuário e o acervo.

Inerente à Arquivologia, nota-se a presença destas quatro dimensões que auxiliam o arquivista e também o usuário a apresentar uma visão holística das instituições e de sua documentação. O código de ética do arquivista, as ações de difusão propostas pelo arquivo e para os usuários, as políticas públicas que envolvem a manutenção das instituições e a conservação dos acervos, bem como a técnica empregada pelos profissionais no momento de exercer atividades como a descrição documental, são exemplos do caráter integrador que as dimensões assumem na Arquivologia.

No entanto, as dimensões da competência em informação não estão presentes somente no cotidiano do profissional. Antes mesmo de desenvolver a prática, o estudante de graduação em Arquivologia já convive com a presença "da competência" nas disciplinas e conteúdos curriculares dos cursos, os quais as enfatizam em suas diretrizes, como observado nos Projetos Pedagógicos, juntamente ao tópico que estabelece o perfil dos egressos das universidades pesquisadas.

Diante do estudo nas três universidades representantes dos cursos de Arquivologia da região Sul do Brasil, identificou-se a presença das quatro dimensões da competência em informação em momentos distintos. A dimensão 
ética está correlacionada ao que diz respeito ao agir com polidez junto à documentação e respeitar os princípios éticos da profissão. A dimensão estética, ao identificar as necessidades dos usuários da informação e apresentar o arquivo, neste caso, utilizando-se de estratégias de marketing, por exemplo. A dimensão técnica diz respeito à compreensão e aplicação de princípios, funções e normatizações arquivísticas, colocando em prática estratégias de gestão documental arquivística. Já a dimensão política, foi observada na relação do arquivista com a comunidade que interagirá com os serviços de informação arquivística.

Considerar que as dimensões da competência em informação estão presentes no processo de formação dos cursos em Arquivologia denota em que bases eles estão calcados, pois é possível visualizá-los de maneira holística, considerando a relação da ciência com a informação documental, com a formação do profissional e os usuários dos arquivos, bem como denota o caráter social/político/cultural (vinculado especialmente ao direito de acesso à informação) e a interdisciplinaridade da Arquivologia.

\section{Referências}

ALDABALDE, Taiguara Villela. Arquivologia e pedagogia arquivística: bases para uma habilitação que ensine o arquivista a educar. In: MARIZ, Anna Carla Almeida; JARDIM, José Maria; SILVA, Sérgio Conde de Albite (Org.). Novas dimensões da pesquisa e do ensino da Arquivologia no Brasil. Rio de Janeiro: Móbile, 2012. p. 198-212.

AMERICAN LIBRARY ASSOCIATION. About ALA. 2016a. Disponível em: <http://www.ala.org/aboutala/>. Acesso em: 16 nov. 2016.

AMERICAN LIBRARY ASSOCIATION. Association of College and Research Libraries. Information literacy competency standards for higher education (October 1999, January 2000, February 2004). 2016b. Disponível em: <http://www.ala.org/acrl/standards/informationliteracycompetency>. Acesso em: 16 nov. 2016.

ANASTASIOU, Léa das Graças Camargo. Propostas curriculares em questão: saberes docentes e trajetórias de formação. In: CUNHA, Maria Isabel da (Org.). Reflexões e práticas em pedagogia universitária. Campinas: Papirus, 2007. cap. 3, p. 43-62. 
ARAÚJO, Carlos Alberto Ávila. Arquivologia, Biblioteconomia, Museologia e Ciência da Informação: o diálogo possível. Brasília: Briquet de Lemos, 2014.

ASSMANN, Hugo. Reencantar a educação: rumo à sociedade aprendente. 8 . ed. Petrópolis: Vozes, 2004.

BELLOTTO, Heloísa Liberalli. Difusão editorial, cultural e educativa em arquivos. In: BELLOTTO, Heloísa Liberalli. Arquivos permanentes: tratamento documental. 4. ed. Rio de Janeiro: FGV, 2006. cap. 14, p. 227-247.

BLUNDELL, Shelley. Archival literacy in action: exploring information literacy capabilities in the Ludy T. Benjamin, Jr. Popular Psychology Magazine collection. 2013. Disponível em: <http://www.ohioarchivists.org/wpcontent/uploads/2013/07/Blundell_soa_2013-04_handout_archlit.pdf>. Acesso em: 16 nov. 2016.

BORKO, Harold. Information Science: What is it? American Documentation, [S.1.], v. 19, n. 1, p. 3-5, jan. 1968. Disponível em:

<https://www.marilia.unesp.br/Home/Instituicao/Docentes/EdbertoFerneda/k--artigo-01.pdf>. Acesso em: 16 nov. 2016.

BOTTINO, Marisa. Panorama dos cursos de Arquivologia no Brasil: graduação e pós-graduação. Arquivo \& Administração, Rio de Janeiro, v. 15, n. 23, p.12$18,1994$.

BRASIL. Lei ${ }^{\circ} 12.343$, de 2 de dezembro de 2010. Institui o Plano Nacional de Cultura - PNC, cria o Sistema Nacional de Informações e Indicadores Culturais SNIIC e dá outras providências. Diário Oficial [da] União, Brasília, 3 dez. 2010. Disponível em: <https://www.planalto.gov.br/ccivil_03/_ato20072010/2010/lei/112343.htm>. Acesso em: 16 nov. 2016.

BRASIL. Ministério do Trabalho e Emprego. Classificação brasileira de ocupações. 2016. Disponível em:

<http://www.mtecbo.gov.br/cbosite/pages/pesquisas/BuscaPorTitulo.jsf〉. Acesso em: 16 nov. 2016.

BRASIL. Parecer CNE/CES 492/2001. 2001. Disponível em: <http://portal.mec.gov.br/cne/arquivos/pdf/CES0492.pdf>. Acesso em: 16 nov. 2016.

CARINI, Peter. Information literacy for archives and special collections: defining outcomes. Libraries and the Academy, Baltimore, v. 16, n. 1, p.193208, 2016. Disponível em:

$<$ https://www.press.jhu.edu/journals/portal_libraries_and_the_academy/portal_p re_print/articles/16.1carini.pdf>. Acesso em: 16 nov. 2016. 

informação e os cursos de graduação em Arquivologia do sul do Brasil

Fernanda Frasson Martendal, Eva Cristina Leite da Silva, Elizete Vieira Vitorino

CONSELHO INTERNACIONAL DE ARQUIVOS. Código de ética. 1996.

Disponível em: <http://www.ica.org/sites/default/files/ICA_1996-09-06_code of ethics_PT.pdf>. Acesso em: 16 nov. 2016.

\section{CONSELHO NACIONAL DE ARQUIVOS. Cursos de Arquivologia no}

Brasil. 2016. Disponível em:

<http://www.conarq.arquivonacional.gov.br/links/389-cursos-de-Arquivologiano-brasil.html>. Acesso em: 16 nov. 2016.

COUTURE, Carol. La politique de gestion des archives. In: COUTURE, Carol (Org.). Les fonctions de l'Archivistique contemporaine. Québec: Presses Universitaires du Québec, 2003. p. 14-30.

COUTURE, Carol; MARTINEAU, Jocelyne; DUCHARME, Daniel. A formação e a pesquisa em arquivística no mundo contemporâneo. Tradução Luís Carlos Lopes. Brasília: FINATEC, 1999.

DUDZIAK, Elisabeth Adriana. Information literacy: princípios, filosofia e prática. Ciência da Informação, Brasília, v. 32, n. 1, p. 23-35, jan./abr. 2003. Disponível em:

<http://www.scielo.br/scielo.php?script=sci_arttext\&pid=S0100$19652003000100003>$. Acesso em: 16 nov. 2016.

JARDIM, José Maria. O conceito e a prática de gestão de documentos. Acervo: Revista do Arquivo Nacional, Rio de Janeiro, v. 2, n. 2, p. 35-42, jul./dez. 1987. Disponível em:

<http://www.arquivonacional.gov.br/media/v.2,n.2,jul.dez.1987.pdf>. Acesso em: 16 nov. 2016.

MARQUES, Angélica Alves da Cunha. Interlocuções entre a Arquivologia nacional e a internacional no delineamento da disciplina no Brasil. 2011. 399 f. Tese (Doutorado) - Programa de Pós-Graduação em Ciência da Informação, Universidade de Brasília, Brasília, 2011. Disponível em: <http://repositorio.unb.br/bitstream/10482/8730/1/2011_Angelica\%20Alves\%20 da\%20Cunha\%20Marques.pdf>. Acesso em: 16 nov. 2016.

MONTEIRO, Agostinho Reis. Profissionalidade e suas refracções. Medi@ções, Setúbal, v. 1, n. 2, p. 5-11, 2010. Disponível em:

<http://mediacoes.ese.ips.pt/index.php/mediacoesonline/article/view/31/pdf_6>. Acesso em: 16 nov. 2016.

ORELO, Eliane Rodrigues Mota; VITORINO, Elizete Vieira. A dimensão estética (sensível) da competência informacional. Encontros Bibli, Florianópolis, v. 18, n. 38, p. 1, set./dez. 2013. Disponível em: $<$ https://periodicos.ufsc.br/index.php/eb/article/view/31455/25971>. Acesso em: 16 nov. 2016. 

informação e os cursos de graduação em Arquivologia do sul do Brasil

Fernanda Frasson Martendal, Eva Cristina Leite da Silva, Elizete Vieira Vitorino

ORGANIZAÇÃO DAS NAÇÕES UNIDAS. Declaração Universal dos Direitos Humanos. 1948. Disponível em: <http://www.dudh.org.br/wpcontent/uploads/2014/12/dudh.pdf>. Acesso em: 16 nov. 2016.

PELLEGRINI, Eliane; VITORINO, Elizete Vieira. A dimensão ética da competência informacional dos bibliotecários do Instituto Federal de Educação, Ciência e Tecnologia de Santa Catarina. In: ENCONTRO NACIONAL DE PESQUISA EM CIÊNCIA DA INFORMAÇÃO, 16., 2015, João Pessoa. Anais... João Pessoa: [s.n.], 2015. Disponível em: <http://www.ufpb.br/evento/lti/ocs/index.php/enancib2015/enancib2015/paper/v iewFile/2667/1065>. Acesso em: 16 nov. 2016.

RIOS, Terezinha Azeredo. Compreender e ensinar: por uma docência de melhor qualidade. 6. ed. São Paulo: Cortez, 2006.

TANODI, Aurelio. The status of archivists in relation to other information professionals in the public service in Latin America. Paris: UNESCO, 1985.

UNIVERSIDADE ESTADUAL DE LONDRINA. Resolução CEPE/CA N. 126/2013. Reformula o Projeto Pedagógico do curso de Arquivologia Habilitação: Geral, a vigorar a partir do ano letivo de 2014. Londrina, 2013. Disponível em:

<http://www.uel.br/prograd/docs_prograd/resolucoes/2013/resolucao_126_13.p df $>$. Acesso em: 16 nov. 2016.

UNIVERSIDADE FEDERAL DE SANTA CATARINA. Projeto Pedagógico do Curso de Graduação em Arquivologia. Florianópolis, 2015. Disponível em: <http://arquivologia.ufsc.br/files/2016/05/PROJETO-PEDAGOGICO-DOCURSO.pdf>. Acesso em: 16 nov. 2016.

\section{UNIVERSIDADE FEDERAL DO RIO GRANDE DO SUL. Projeto}

Pedagógico do Curso de Arquivologia. Porto Alegre, 2014. Disponível em: <http://www.ufrgs.br/fabico/documentos-graduacao-e-comgrads/comgradaq1/projeto-pedagogico-Arquivologia-2014>. Acesso em: 16 nov. 2016.

VITORINO, Elizete Vieira. Análise dimensional da competência em informação: bases teóricas e conceituais para reflexão. Revista IberoAmericana de Ciência da Informação, Brasília, v. 9, n. 2, p. 421-440, jul./dez. 2016. Disponível em:

<http://periodicos.unb.br/index.php/RICI/article/view/16051/13702>. Acesso em: 6 dez. 2016.

VITORINO, Elizete Vieira; PIANTOLA, Daniela. Dimensões da competência informacional (2). Ciência da Informação, Brasília, v. 40, n. 1, p. 99-110, jan./abr. 2011. Disponível em:

<http://www.scielo.br/pdf/ci/v40n1/a08v40n1.pdf>. Acesso em: 16 nov. 2016. 


\title{
Dialogue among the dimensions of the information literacy and the undergraduate courses of Archival Science of the south of Brazil
}

\begin{abstract}
This essay aims to identify how the four dimensions of the information literacy are related to the proposed objectives of the wanted profile for the graduated students of the undergraduate courses of Archival Science of three universities of the south of Brazil: Universidade Estadual de Londrina, Universidade Federal de Santa Catarina e Universidade Federal do Rio Grande do Sul. About the methodological aspects, it is identified as an exploratory and bibliographic research and it proposes to think the Archival Science as a science that contemplates the theoretical, practical aspects, imbued with guidelines and dialogues among the professionals, the fonds and their users. The research considered that the four dimensions of the information literacy (technical, aesthetic, ethic and political) are related to the profile of the graduated students by the Pedagogical Projects of the three universities and this weighing contributes to think the Archival Science into its macro space.
\end{abstract}

Keywords: Information literacy. Archival Science. Dimensions of the information literacy. Profile of the gratuated students of the undergraduate course of Archival Science.

Recebido: 10/12/2016

Aceito: 21/03/2017

\footnotetext{
${ }^{1}$ Sobre a interdisciplinaridade, cabe destacar as contribuições de Assmann (2004, p. 162) sobre este assunto: trata-se do "[...] enfoque científico e pedagógico que se caracteriza por buscar algo mais do que mera justaposição das contribuições de diversas disciplinas sobre um mesmo assunto, e se esforça por estabelecer um diálogo enriquecedor entre especialistas de diversas áreas científicas sobre uma determinada temática."

${ }^{2}$ Quanto à transdisciplinaridade, também Assmann (2004, p. 182) nos orienta para um "[...] enfoque científico e pedagógico que torna explícito o problema de que um diálogo entre diversas disciplinas e áreas científicas implica necessariamente uma questão epistemológica." Para o autor, a transdisciplinaridade não pretende desvalorizar a competência disciplinar específica, mas sim elevá-la a um patamar de conhecimentos melhorados nas áreas disciplinares (ASSMANN, 2004).

${ }^{3}$ A American Library Association (ALA) foi fundada em 1876 durante a Centennial Exposition na Filadélfia. Sua missão é “[...] fornecer liderança para o desenvolvimento, promoção e melhoria de bibliotecas e serviços de informação bem como para a profissão de bibliotecário a fim de aumentar a aprendizagem e garantir acesso à informação para todos." (AMERICAN LIBRARY ASSOCIATION, 2016a, tradução nossa).
} 